
Options

\title{
Book Review: Plieninger, T., and C. Bieling. 2012. Resilience and the Cultural Landscape - Understanding and Managing Change in Human- Shaped Environments. Cambridge University Press, Cambridge
}

\author{
Jennifer Hauck $^{1}$
}

In their book, Resilience and the cultural landscape-understanding and managing change in human-shaped environments, the editors Plieninger and Bieling bring together cultural landscape and resilience approaches to provide new insights into the socialecological resilience of cultural landscapes. They have combined 19 contributions from a broad scholarship of both communities, written in an accessible and engaging style. The book is for anyone interested not only in analyzing but also in managing change in human-shaped environments in the context of sustainability.

The chapters are organized in four parts. Part I, "Conceptualising landscapes as social-ecological systems," offers six contributions with critical, theoretical insights about the resilience conceptual framework, a variety of cultural landscape approaches, and possible combinations thereof. After Plieninger and Bieling set the stage in their introductory chapter, Selman provides a broad view of the general applicability of resilience thinking to landscape research. He highlights the importance of carefully analyzing drivers of change when designing landscape management because "local is not always desirable and global is not always undesirable." Kirchhoff et al. uncover the implicit values inherent in resilience thinking and problematize the associated preferences for management as particularistic, i.e., not necessarily reflecting the interests of the majority of stakeholders involved. Head criticizes how the human (social) has been conceptualized as separate to and distinct from the nonhuman (ecological) world. Drawing on anglophone sources, she examines how the human-nature relationship has been conceptualized in the cultural landscape literature and provides alternative relational perspectives. Another critical but also constructive chapter is provided by Stenseke et al. The authors suggest an 'arena' approach instead of a systems approach to cover the multifunctionality of landscapes and associated complexity of power relations between land-use interests. Widgren concludes the section by demonstrating how the concept of political ecology could help to overcome the often shallow treatment of the social dimension in resilience thinking. Apart from stressing the need for an historical perspective, he argues for an understanding of social stratification, control of labor, access to land, and links to the wider world as important dynamic forces.

The five regional case studies in Part II, "Analysing landscape resilience," illustrate how land-use change can be explored using cultural landscape and resilience perspectives. Based on a case study from the Swiss Limpach valley, Bürgi et al. propose an integrated analysis of landscape change, the concept of ecosystem services, and the driving forces framework for systematically assessing the resilience of cultural landscapes with regard to the provision of ecosystem services. The chapter impressively shows that the value of a landscape and its services is in the eye of the beholder. Rescia et al. analyze cultural landscapes as complex adaptive systems with examples of case studies from northern Spain and northern Argentina. Röhring and Gailing introduce the concept of path dependencies and show in their case studies of man-made floodplain landscapes in Brandenburg that different understandings of what resilience means in relation to cultural landscapes can exist side by side, and attempts should be made to integrate them for improved management. Found and Berbés-Blázquez illustrate the use of the heuristics of adaptive cycles and panarchy to understand the resilience of the sugar cane landscapes of a number of Caribbean islands, despite the fact that for many, slaves in particular, this kind of resilience was not desirable. Taking a forward looking perspective, Gee and Burkhard analyze the potential impacts of a regime shift toward more socioeconomic resilience by looking at scenarios of offshore wind farming on Germany's North Sea coast.

Part III of the book, "Managing landscapes for resilience," contains five regional case studies addressing landscape management. In her contribution, Prager aims to derive insights on the role of collaborative groups for the resilience of cultural landscapes. Unfortunately, the coarse comparison between Germany, UK, Austria, and the Netherlands does, as the author herself admits, not allow the drawing of conclusions on how the resilience of a social system influences the overall resilience of a social-ecological system. A response strategy assessment, analyzing coping, adaptive, and transformative strategies of actors to disturbance, is introduced by Tuvendal and Elmqvist. Using the example of southern Sweden, they show how such an assessment can be used to estimate the resilience of the associated social-ecological systems. Oteros-Rozas et al. use the ecosystem services framework to explore the resilience of transhumance cultural landscapes in Spain and draw conclusions about how traditional land-use practices contribute to the provision of a wide variety of ecosystem services. Van der Stege et al. provide an insight into how traditional home gardens contribute to the resilience of their owners and associated local communities in times of political and socioeconomic changes. Similar to other chapters, Beymer-Farris et al. criticize the lack of attention currently paid by the resilience thinking to power relation and asymmetries in the conceptualization and prescriptions of adaptive management solutions. Through a combined political ecology and resilience approach, the authors then explore, with a case study from southern Asia to East Africa, the consequences of global shifts in industrial prawn farming. 
The last part of this edited volume, "Perspectives for resilient landscapes," synthesizes the main findings of the book from different viewpoints starting with Crumley, who takes an archaeological perspective. She provides a historical analysis of the resilience of Burgundian landscapes. Crumley suggests a heterarchy of theoretical, conceptual, and methodological tools to think about systemic change in temporal, spatial, and cognitive dimensions and to derive recommendations for resilient futures. One of the highlights of the book is presented by Kinzig. Having studied the resilience literature extensively, she reflects on the criticisms of previous chapters, identifying some as prejudices and some as substantial shortcomings of resilience thinking. The editors Plieninger and Bieling conclude the book by highlighting the advantages of combining the resilience and cultural landscapes perspectives.

I share the conclusions of the editors that the combination of the resilience perspective and cultural landscape approaches is not only possible but produces a number of benefits, i.e., the communities indeed complement each other. The resilience framework provides a systematic and comprehensive framework that reveals patterns and principles, thus allowing the transfer of insights across space, time, and communities to learn from each other. It would have probably helped scholars unfamiliar with the cultural landscape literature to have a chapter providing an overview of the different strands of landscape research and what they have to offer. However, the various concepts and methods of cultural landscape scholarship described in the different chapters of the book provide very good introductions and alternative perspectives, e.g., how to overcome the blind spots of resilience thinking, namely social and historical aspects. Further, I share the warning repeated by a number of chapter authors and supported by empirical findings that both approaches are value laden. Both communities must pay attention to avoid the normative trap by reflecting on their own biases and, more importantly, by stakeholder engagement, before giving management recommendations. I can highly recommend this book for the landscape as well as for the resilience scholarship and more generally for everybody interested in analyzing and managing change in human-shaped environments in the context of sustainability.

\section{Book information:}

Plieninger, Tobias, and Claudia Bieling. 2012. Resilience and the Cultural Landscape - Understanding and Managing Change in Human-Shaped Environments. Cambridge University Press, Cambridge, UK. 348 pp., hardcover \$70.00 ISBN 978-1-107-02078-8.

Responses to this article can be read online at: http://www.ecologyandsociety.org/issues/responses. $\mathrm{php} / 6226$ 